thrombosis? The classic paediatric textbooks were not of much help since they made no mention of muscle pain in SHS.

The results of the laboratory investigations did not contribute additional information. The muscle enzyme studies showed normal values in two patients and a slight increase in one. Electromyography of the gastrocnemius in one of the patients was normal. Eventually it seemed quite obvious that our patients were just bleeding into their leg muscles and since the symptoms abated so quickly we decided against a muscle biopsy. It is interesting that all our three children were in hospital during a five month period (October 1982-March 1983). By the time the third patient was admitted we felt confident in our assurance to the anxious parents that their son would soon run again.

In conclusion, we do not claim to contribute to the understanding of this enigmatic entity but we would emphasise the form that the muscle involve- ment in SHS may take, the intriguing predilection of the disease to the lower half of the body, and the fact that muscle pain in all our patients washow could it be otherwise-symmetrical!

\section{References}

1 Gairdner D. The Schönlein-Henoch syndrome (anaphylactoid purpura). QJ Med 1948;17:95-122.

2 Allen DM, Diamond LK, Howell DA. Anaphylactoid purpura in children (Schönlein-Henoch syndrome): review with a follow-up of the renal complications. $\mathrm{Am}$ J Dis Child 1960;99:833-54.

3 Meadow R. Schönlein-Henoch syndrome. In: CM Edelmann, Jr, ed. Paediatric kidney disease. Boston: Little Brown, 1978:790.

4 Meadow R. Schönlein-Henoch syndrome. Arch Dis Child 1979;54:822-4.

Correspondence to Dr E Somekh, Department of Paediatrics, The Edith Wolfson Hospital, Holon, Israel.

Received 22 June 1983

\title{
Visceral leishmaniasis contracted in the Mediterranean area
}

\section{A S KHOT AND M H THOMPSON}

Royal Alexandra Hospital for Sick Children, Brighton
SUMMARY Two infants who presented with anaemia and hepatosplenomegaly were found to have visceral leishmaniasis. Diagnosis was made immediately after bone marrow aspiration in one infant, but in the other there was considerable delay. Both responded well to a course of sodium stibogluconate.

Visceral leishmaniasis (kala-azar) is endemic in many Mediterranean countries including the popular tourist areas of Southern France, Spain, Portugal, Malta, Italy, and Greece. ${ }^{123}$ We describe two children recently referred to this hospital who were found to have visceral leishmaniasis. In neither case was the diagnosis of visceral leishmaniasis considered initially, although in retrospect both children had the typical symptoms and signs of the disease and had visited or lived in countries where it is endemic.

\section{Case 1}

An 8 month old girl born of English parents on a farming commune in Spain, came to England in March 1980. She had been well until four months of age when she developed a dry cough, progressive anorexia, and lethargy. Her weight had fallen and her development had slowed.

Physical examination showed pallor, low grade pyrexia, pretibial oedema, massive splenomegaly (the spleen extending into the right iliac fossa), and a liver palpable $3 \mathrm{~cm}$ below the right costal margin. Investigations showed haemoglobin $6 \cdot 2 \mathrm{~g} / \mathrm{dl}$, reticulocytes $3.5 \%$, white blood count $6.4 \times 10^{9} / 1(6400 / \mu l)$, neutrophils $4 \%$, lymphoyctes $84 \%$ and platelets $32 \times 10^{9} / 1 \quad(32000 / \mu l)$. An initial diagnosis of malignant disease was considered but a bone marrow biopsy showed numerous amastigotes (Leishman-Donovan bodies).

She was transfused with packed cells, started on antibiotics, and treated with sodium stibogluconate ( $25 \mathrm{mg} / \mathrm{kg}$ bodyweight, IV) daily for three weeks. After this time her hepatosplenomegaly had decreased considerably and her haemoglobin, white blood count, and platelet values were returing to normal. Five weeks later she relapsed, with increasing hepatosplenomegaly and marked neutropenia. She was given a further three week course of sodium stibogluconate in the same dose and made an uneventful recovery.

A year later she was followed up and found to be well. It was later discovered that another infant 


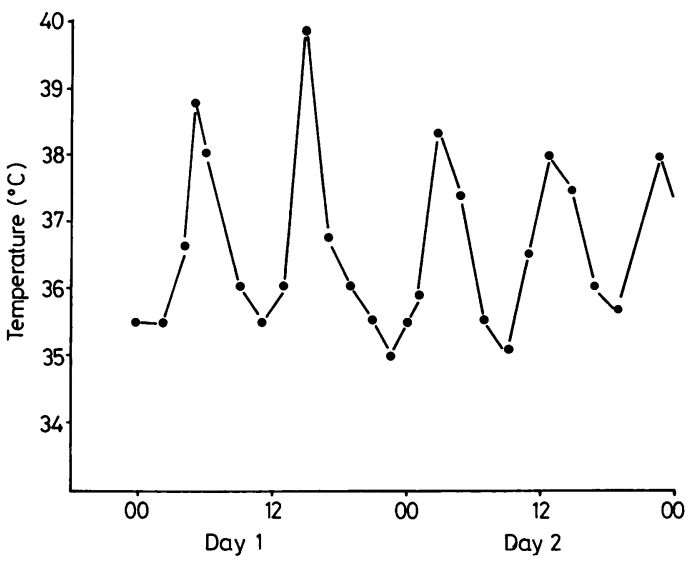

Figure Temperature chart (child in case 2) showing the classic intermittent fever of visceral leishmaniasis.

from the same commune had been treated for visceral leishmaniasis in Germany.

\section{Case 2}

A 10 month old girl was referred with a month's history of malaise, anorexia, vomiting, a dry cough, and an intermittent fever (see Figure). Her birth and past history had been unremarkable apart from two weeks spent in the Algarve, Portugal in October 1981, when she was 6 months old. Clinical examination showed a miserable, anaemic child with marked hepatosplenomegaly-the spleen being palpable $6 \mathrm{~cm}$ and the liver $4 \mathrm{~cm}$ below the costal margins. Malignant disease was again considered. Investigations showed haemoglobin $8.5 \mathrm{~g} / \mathrm{dl}$, reticulocytes $15 \%$, white blood count $5.79 \times 10^{9} / 1(5790 / \mu l)$, neutrophils $19 \%$, lymphocytes $78 \%$ and platelets $70 \times 10^{9} / 1(70000 / \mu 1)$. Bone marrow showed hyperplasia with no evidence of malignancy.

In spite of extensive investigations in this hospital and at the Hospital for Sick Children, London, no diagnosis was made. A diagnosis of leishmaniasis was considered, but there was no haematological and histological proof. She deteriorated further and was begun, empirically, on sodium stibogluconate 7 weeks after admission. The original bone marrow, a liver biopsy specimen, and a sample of serum were then sent to the Hospital for Tropical Diseases, London, where amastigotes were identified in both tissues. Antibodies to leishmania were detected be indirect immunofluorescence at a titre of 1 in 40 . Treatment with sodium stibogluconate was continued for 30 days: 8 months later she was thriving and her hepatosplenomegaly had resolved.

\section{Discussion}

Visceral leishmaniasis is well documented in Mediterranean countries where stray dogs provide the reservoir of infection; the disease being transmitted to man by the phlebotomine sand flies. In man the parasite proliferates in the reticuloendothelial system causing the characteristic blood picture of hypersplenism. ${ }^{4}$ Most cases occur in children under the age of four years. The incidence in Mediterranean countries may be increasing. ${ }^{2}$

The onset may be gradual or acute. After an incubation period of three to four months, the child becomes ill with anorexia, lassitude, and an intermittent pyrexia: cough and diarrhoea are common. Anaemia, hepatomegaly, and marked splenomegaly are found on examination. There is notable immunosuppression and often secondary infection. ${ }^{5}$ In $90 \%$ of cases, the diagnosis may be made from smears of bone marrow aspirates. ${ }^{1}$ Liver biopsy and splenic aspiration may also be helpful. Antibodies appear early and are detectable by several methods. A pentavalent antimonial such as sodium stibogluconate is the drug of choice and children under the age of five years should receive $20 \mathrm{mg}$ antimony/ $\mathrm{kg}$ bodyweight (minimum $200 \mathrm{mg}$ antimony) for at least three weeks. ${ }^{6}$

The prognosis is usually excellent, provided appropriate treatment is started in time. Clinical and laboratory staff, often unfamiliar with the disease and its diagnosis, should seek expert advice sooner rather than later.

We thank Dr Bryceson of the Hospital for Tropical Diseases, London and Dr Killick-Kendrick of Imperial College, Sillwood Park for help and advice.

\section{References}

1 Manson Bahr PEC, Apted FIC. Manson's tropical diseases. 18th edition. London: Balliere Tindall, 1982: 93-104.

2 Abranches P, Alves Pires C. O kala-azar em Portugal. Revista Portuguesa de Doencas Infecciosas 1980;11: 203-17.

3 Cachia EA, Fenech FF. A review of kala azar in Malta from 1947 to 1962. Trans R Soc Trop Med Hyg 1964;58: 234-41.

4 Li Volti S, Fischer A, Musumeci S. Hematological and serological aspects of Mediterranean kala-azar in infancy and childhood. Acta Trop (Basel) 1980;37:351-65.

5 Ho M, Koech DK, Iha DW, Bryceson ADM. Immunosuppression in Kenyan visceral leishmaniasis. Clin Exp Immunol 1983;51:207-14.

6 Anabwani GM, Ngira JA, Dimiti G, Bryceson ADM. Comparison of two dosage schedules of sodium stibogluconate in the treatment of visceral leishmaniasis in Kenya. Lancet $1983 ; \mathbf{i}: 210-3$.

Correspondence to Dr A S Khot, Royal Alexandra Hospital for Sick Children, Brighton BN1 3JN.

Received 6 July 1983 